\title{
LA II EDAD DEL HIERRO Y LA ÉPOCA ROMANA EN LA RIOJA: DOS DÉCADAS DE INVESTIGACIÓN (1974-1994)
}

\author{
María Josefa Castillo Pascual*
}

\begin{abstract}
RESUMEN: La finalidad del presente artículo es estudiar veinte años de investigación histórica en torno a La Rioja, ciñéndoños a dos periodos: la II Edad del Hierro y la Época Romana. A pesar de la abundacia de publicaciones, sobre todo en relación con La Rioja romana, ciertos aspectos siguen todavía inéditos, otros necesitan una revisión y, en general, la Protohistoria e Historia Antigua de La Rioja necesitan partir de otros planteamientos.
\end{abstract}

ZUSAMMENFASSUNG: Dieser Aufsatz, behandelt die Forschungsgeschichte der Jahre 1974 bis 1994 von Archäologie und Geschichtswissenschaft über das Gebiet La Rioja während der II. Eisenzeit und der römischen Zeit unter besonderer Berücksichtigung richtungsweisender Arbeiten.

El conjunto está dividido en dos grandes grupos temáticos, el primero dedicado a la II Edad del Hierro y el segundo a la fase de dominio romano. Nos centraremos principalmente en aquellos trabajos que han supuesto un avance en la reconstrucción de estas dos etapas en tierras riojanas, recogiendo el resto en la bibliografía que figura al final, cuyo objetivo primordial es completar el estudio bibliográfico publicado por Espinosa en 1981 (ESPINOSA 1981). Somos conscientes de que puede no estar exenta de olvidos, siempre involuntarios, como es el caso de algunas de las tesinas

* Profesora del Departamento de Ciencias Humanas y Sociales, Área de Historia Antigua, de la Universidad de La Rioja. 
de licenciatura y tesis doctorales leídas durante estos veinte años y a las que no hemos podido acceder por permanecer aún inéditas.

\section{La II EDAD DEL HierRo en La Rioja}

En la II Edad del Hierro los berones eran el pueblo prerromano de origen indoeuropeo que habitaba la casi totalidad de La Rioja ${ }^{1}$. El territorio berón limitaba al norte con el sur de Alava y Navarra, al este con la comarca calagurritana ${ }^{2}$; su frontera sur era una línea que se extendía desde el norte de la sierra de la Demanda, siguiendo por Urbión, Cebollera hasta las sierras de Pinedo y Ayedo de Santiago, excluyéndose los valles altos del Najerilla y del Alhama; y, por último, el rio Tirón era su límite occidental. Pero La Rioja fue también tierra de Austrigones, que habitaban al oeste del río Tirón, de Arevacos y Pelendones cuyo territorio incluía La Rioja meridional (los valles altos del Najerilla y del Alhama) y de vascones que a partir de las guerras celtibéricas se extendieron por el Alto Aragón y la ribera navarro-riojana ${ }^{3}$.

En relación con el poblamiento berón en La Rioja destacamos la monografía de Villacampa (VILLACAMPA 1980), producto de su memoria de licenciatura, cuyas conclusiones ya publicó en 1978 (VILLACAMPA 1978). El propósito de la autora ha sido la recopilación, el análisis, la crítica y la interpretación de los testimonios que las fuentes escritas nos aportan en torno al pueblo berón, modificando y suprimiendo pasajes y recogiendo los testimonios no incluidos en estudios anteriores, sin dejar a un lado los restos arqueológicos y epigráficos más destacados, así como los numismáticos ${ }^{4}$. A partir de este plantemiento reconstruye el entorno geográfico e histórico del pueblo berón, sus orígenes y etapas de asentamiento, su ubicación, los límites de su territorio, las vías de comunicación que lo surcaban, los núcleos poblacionales más importantes que más tarde cayeron dentro del área de influencia romana, la reacción berona ante el invasor, su participación en las luchas civiles de Roma que tuvieron como escenario la Península Ibérica y su posterior romanización, su existencia durante el Bajo Imperio y, por último, hace una referencia puramente descriptiva, única posible ante la exigüidad de los testimonios, a aspectos de la economía, sociedad, religión, costumbres y modos de vida en el territorio berón.

También merece ser destacado el estudio de Castiella (CASTIELLA 1977) sobre la Edad del Hierro en Navarra y La Rioja. En este trabajo nos presenta la autora un completo catálogo de los yacimientos (poblados, necrópolis y cuevas) hasta ese momento conocidos, aportando una mayor información sobre alguno de ellos y algu-

1.En el topónimo Logroño queda también patente la importancia del poblamiento berón en La Rioja como lo demuestra Espinosa (ESPINOSA 1993).

2. Después de las guerras celtibéricas los vascones descienden hacia el sur y el límite con los berones es una línea que pasa por Yanguas, Enciso, Arnedo, El Redal y Alcanadre.

3. Sobre los vascones en La Rioja: PEREX AGORRETA 1986.

4.Sobre la transmisión de noticias acerca de los berones entre los escritores griegos: PÉREZ VILATELA 1988. 
nos materiales hasta ahora inéditos ${ }^{5}$. Sobre cada asentamiento catalogado ofrece su concreta ubicación geográfica, una historia de la investigación, referencias bibliográficas, su valoración y la descripción de los hallazgos. Destaca la parte dedicada al estudio del material cerámico, parte en la que la autora se ha tenido que enfrentar a dos handicaps que a lo largo de estos veinte años y ya desde antes están presentes en la arqueología riojana: la ausencia de un método científico en muchas excavaciones que ha supuesto el establecimiento de estratigrafías imprecisas y el conocimiento de muchos yacimientos tan sólo a través de los hallazgos de superficie. Dentro de esta perspectiva general y de síntesis hay que situar la memoria de licenciatura de Diarte (DIARTE 1987) que define las características del territorio riojano durante la II Edad del Hierro dentro del horinzonte cultural celtibérico, sin aislarlo de los poblamientos prerromanos de Navarra y Aragón. En el catálogo de yacimientos que presenta recoge, además de los ya conocidos por Castiella, los nuevos descubrimientos.

El resto de los trabajos sobre la II Edad del Hierro en La Rioja se centran principalmente en yacimientos concretos y se pueden dividir en tres grupos: 1) aquellos que dan noticia del yacimiento a partir de una prospección de superficie motivada por un hallazgo casual, un vecino al hacer una zanja o, en el peor de los casos, las labores de extracción de grava son la causa de algunos descubrimientos y también la causa de la destrucción inmediata de la casi totalidad de los mismos; 2) las publicaciones que son fruto de campañas de excavación durante uno o más años y que ofrecen una visión precisa y global del yacimiento; y 3) las publicaciones que se limitan a dar noticia de hallazgos sueltos, fuera de contexto arqueológico y que apenas ofrecen información sobre el yacimiento o sobre la zona en la que, a veces supuestamente, se han encontrado.

Dentro del primer grupo incluímos las publicaciones sobre el yacimiento celtibérico del Cerro de San Miguel (Arnedo) (CASTIELLA 1975; FERNÁNDEZ DE BOBADILLA 1976) ${ }^{6}$; el de El Cortijo (Bergasa) que es considerado por Pascual y Moreno "como un lugar de máximo interés para el estudio de una problemática que ya Pellicer planteó en su día, como es el influjo de la cerámica ibérica en el Valle del Ebro", (MORENO/ PASCUAL 1977-78: 413), en él los autores han localizado uno o más hornos de cerámica?. Conocimiento a nivel de hallazgos de superficie tenemos

5. Los yacimientos de la zona riojana correspondientes a la II Edad del Hierro que se recogen en este trabajo son los siguientes: Libia en Herramélluri (pp. 84-105); Monte Cantabria en Logroño (pp. 105-107); Partelapeña en El Redal (pp. 127-152), yacimiento de la I Edad del Hierro que continuó débilmente poblado durante la segunda, perviviendo hasta el s. I d.C. (ALVÁREZ CLAVIJO/ MINGUEZ 1989); Las Bodegas y Las Posadas en Alberite (pp. 117-122); Castejoncillo en Montemediano (pp. 162-166); Los Arbolazos, Campobajo, El Valladar y La Torrecilla en Calahorra (pp. 152-154); San Miguel en Arnedo (pp. 154-161); Cerro de la Cividad en Canales de la Sierra (pp. 186-187); Contrebia Leukade en Inestrillas (pp. 187-188); y Teprías y El Villar en Bobadilla (p. 215).

6. Este yacimiento prerromano fue excavado entre 1974 y 1980 por un equipo de la Universidad Autónoma de Madrid, no tenemos constancia de que se hayan publicado las memorias de excavación.

7. Con posterioridad a esta noticia Galve y Lázaro (GALVE/ LÁZARO 1979) presentaron este yacimiento en el XV Congreso Nacional de Arqueología, aportando los datos extraídos de una prospección en 
también sobre los asentamientos prerromanos localizados en los términos de E1 Villar y Teprías en Bobadilla (CASTIELLA 1973: 215) ${ }^{8}$. Un ejemplo más es el yacimiento del Cerro de Santa Ana (Entrena), descubierto por "un paseante solitario, enamorado de tiempos que se fueron y buscador infatigable de sus tesoros" (ESPINOSA/ GONZÁLEZ BLANCO 1977, 1977a). Los hallazgos en superficie recogidos por los autores permiten establecer una secuencia cronológica que va desde los primeros periodos de la Edad del Hierro hasta el s. V d. J.C. y fijar la extensión espacial del poblado por toda la cumbre del cerro, sus vertientes oeste, sur y este hasta la llanura; además el estudio de los planos catastrales de la zona les hace suponer la existencia de una centuriación romana'. Fruto también de paseos casuales es la localización del poblado celtibérico de El Patín (Estollo) del que Ortego (ORTEGO 1976) estudia algunos materiales de superficie.

Dentro del segundo grupo hemos incluido la monografía de Hernández Vera (HERNÁNDEZ VERA 1982) sobre Contrebia Leukade (Aguilar del río Alhama) que es la publicación de su tesis doctoral ${ }^{10}$, y la de Marcos Pous sobre Libia (Herramélluri) (MARCOS POUS 1979). La del primero, a pesar de no ser producto de una excavación sistemática, ofrece un completo y profundo estudio sobre este yacimiento a partir de las conclusiones de Taracena que actualiza y desarrolla, de los materiales depositados en el Museo Provincial de Soria, de los extraídos en numerosas prospecciones, del estudio sobre el terreno de los elementos urbanísticos conservados y de los cortes estratigráficos realizados con el fin de reconstruir la secuencia cronológico-cultural del yacimiento. Como resultado establece tres etapas de ocupación: una primera fase correspondiente al Bronce Final y dentro de la cultura de Cogotas; un primer poblamiento de la I Edad de Hierro (s. VI-IV a. J.C.) en el que a finales del s. IV o principios del s. III a. J.C. se introducen nuevos elementos, los arevacos ocupan el cerro que se rodea de un impresionante sistema defensivo ante la amenaza romana en la zona (en el año 77 a. J.C. Contrebia juega un importante papel en las guerras sertorianas y a mediados del siglo I a. J.C. es destruida definitivamente por Pompeyo); con el dominio romano la población se traslada al llano y durante la época imperial la ciudad permanece prácticamente despoblada; hay que esperar al $\mathbf{s}$. III d. J.C. para que ante la inseguridad general la población regrese al cerro y reconstruya la muralla.

La monografía de Marcos Pous (MARCOS POUS 1979) sobre Libia "casi Memoria de Excavaciones, pretende dar a conocer los resultados obtenidos en el

superficie y del corte estratigráfico que realizaron, pero sin variar lo ya expuesto por Moreno y Pascual (MORENO/ PASCUAL 1977-78).

8. Dados a conocer por primera vez en el año 1973 y recogido por Castiella (CASTIELLA 1975).

9. A los mismos autores debemos la noticia de la existencia de la necrópolis de este poblado, fruto también de un hallazgo casual, y que corresponde a la fase romana de este yacimiento como lo demuestran los ajuares y la estructura de las tumbas ( ESPINOSA/ GONZÁLEZ BLANCO 1976).

10. Un avance de sus conclusiones en: HERNANDEZ VERA 1978. Sobre las recientes campañas de excavación y sus resultados: HERNÁNDEZ VERA et alii 1989, HERNÁNDEZ VERA 1990 y HERNÁNDEZ VERA/ MARTÍNEZ TORRECILLA 1993. 
estudio sobre el terreno, a través de catas de prospección, del solar de la antigua ciudad de Libia, centrándose de forma especial en los trabajos de 1966 que fueron los más intensos" (MARCOS POUS 1979: 9). En la primera parte de su estudio el autor se detiene en consideraciones de tipo historiográfico, en la situación geográfica del yacimiento, sus recursos naturales y extensión, en los sectores prospectados y en el método de prospección empleado. En la segunda parte nos ofrece los resultados de cuatro cortes estratigráficos practicados en tres zonas de prospección que junto con el estudio de los materiales han permitido la siguiente reconstrucción históricoarqueológica: una etapa preimperial dentro de la que distingue tres fases (celtibérica antigua, celtibérica media y celtibérica reciente), a lo largo de este periodo la población concentrada en un principio en la colina de La Llana crecería y se extendería hacia las laderas al mismo tiempo que iba mejorando la estructura de las casas y el urbanismo del poblado; una etapa imperial en la que se observa un lento proceso de romanización y, por último, una etapa tardorromana.

También dentro de este apartado incluímos los estudios sobre el poblamiento prerromano de Monte Cantabria (Logroño) del que se tiene constancia desde las primeras prospecciones realizadas por Taracena en 1942, a las que siguieron algunos sondeos y una primera fase de trabajos arqueológicos (1940-1945). A partir de 1977 se iniciaron nuevas campañas de excavación y un avance de los resultados fueron publicados en 1979 en un monográfico dedicado a la ciudad de Logroño en la revista Cuadernos de Investigación del Colegio Universitario de Logroño (PÉREZ ARRONDO 1979) ${ }^{11}$. A partir de entonces quedaron definidas las tres etapas de ocupación del monte: nivel celtibérico (s. IV-III a. J.C.), nivel tardorromano (s. III-IV d. J.C.) y nivel medieval (segunda mital del s. XII). Posteriores campañas de excavación han servido para la delimitación del hábitat berón y medieval, que volvió a cobrar protagonismo con el proyecto de urbanización de la zona del cerro promovido por el Ayuntamiento de Logroño (PÉREZ ARRONDO 1990; PÉREZ ARRONDO/ ANDRÉS 1983; 1991; PÉREZ ARRONDO et alii 1990).

Los trabajos que se incluyen en el tercer grupo apenas aportan datos válidos para reconstruir las etapas de ocupación del yacimiento, para definir el lugar que éste ocupa dentro de una jerarquía de asentamientos, su funcionalidad o la entidad de su poblamiento. Dentro de esta categoría citemos a modo de ejemplo la publicación de una gema entallada encontrada en Santa Ana (Entrena) (MÉNDEZ/ MORENO), las estelas indígenas de Hormilleja reutilizadas en una necrópolis medieval (MARTÍNBUENO 1975) o fragmentos de cerámica excisa (ESPINOSA/ GONZÁLEZ BLANCO 1976).

No debemos olvidar a la hora de valorar los estudios sobre la Edad del Hierro en La Rioja las circunstancias del hallazgo: el conocimiento que podamos tener sobre

11. Este estudio está completado por un análisis historiográfico de las fuentes medievales centradas en torno a la polémica de identificar Monte Cantabria con la Cantabria arrasada por Leovigildo: VILLACAMPA 1979; y por un estudio de materiales de superficie sin precisión estratigráfica y sin una ubicación exacta: PASCUAL 1979. 
un yacimiento repercute directamente en la determinación de la categoría del mismo. Un hallazgo fortuito impide precisiones en torno a la envergadura del yacimiento, a su potencia arqueológica, a su funcionalidad y a sus etapas de ocupación; en cambio, una campaña de excavación implica la posibilidad de precisar la categoría del asentamiento, poblado o núcleo menor de población.

\section{ÉPOCA ROMANA}

El número de trabajos sobre La Rioja bajo dominio romano es, en comparación con el periodo precedente, mucho mayor aunque ello no implica que se haya abarcado el amplio abánico temático que se encierra en un proceso tan complejo como la conquista romana del valle medio y alto del Ebro y la posterior integración y asimilación de los territorios conquistados. Siguen existiendo lagunas bibliográficas que, según nuestra opinión, no se solucionan engrosando el número de excavaciones, sino ampliando las líneas de investigación y abandonando los inventarios, las tipologías y el método descriptivo por elaboraciones históricas de carácter global, en las que se olviden los localismos. La Rioja no era una unidad histórica en tiempos de Roma sino que estaba inmersa una unidad mayor, el valle del Ebro, que a su vez era una parte de la provincia Tarraconense y de las provincias romanas de Occidente.

Dada la variedad temática y el número de trabajos con los que contamos para La Rioja romana, hemos creído más conveniente y práctico seguir para la exposición y valoración de los mismos un orden temático y así hemos distinguido los siguientes grupos: formas de hábitats y necrópolis, ingeniería romana, industria alfarera, epigrafía y numismática, religión y Tardía Antigüedad.

\section{Formas de HÁBITAT Y NECRÓPOLIS}

Tres son las formas de hábitat que nos econtramos en esta región en época romana: en primer lugar las ciudades, es decir, todos aquellos asentamientos que funcionan como centros de un territorio determinado y que como tales articulaban la vida económica, administrativa, social y cultural del mismo, incluyendo aquellos de los que no tenemos ningún indicio de su estatuto jurídico; en segundo lugar los que clasificamos como núcleos menores, villae por ejemplo, o los asentamientos en los que la falta de una excavación o prospección sistemática impide incluirlos dentro de la primera categoría; y en último lugar las cuevas, la forma de hábitat característica de la Tardía Antigüedad y de la que en La Rioja tenemos sobradas evidencias.

\section{CiUdades}

Las fuentes literarias mencionan cinco núcleos urbanos, en su mayor parte asentamientos indígenas que tras la conquista fueron piezas clave en la ordenación territorial diseñada por Roma para el valle del Ebro, estos núcleos son Calagurris Iulia 
(Calahorra), Graccuriis (Alfaro), Libia (Herramélluri), Tritium Megallum (Tricio) y Vareia (Varea, Logroño).

El primero de ellos, CALAGURRIS IULIA NASSICA, es el asentamiento romano de La Rioja sobre el que más en profundidad se ha trabajado, hecho que es explicable si tenemos en cuenta que fue uno de los enclaves más importante en el valle medio del Ebro durante la conquista y posterior romanización de la zona. En sus comienzos fue un oppidum indígena peregrino y estipendiario que en el periodo de las guerras sertorianas jugó un importante papel en la estrategia desarrollada por Sertorio en el eje del Ebro y por ello fue una de las ciudades sertorianas castigada por Pompeyo $^{12}$; posteriormente paso a integrarse en el ager Vasconum. El florecimiento de la ciudad comienza con Augusto que en sus años de triunviro tuvo una guardia personal de calagurritanos y después fue patrono de la ciudad. En estos momentos Calagurris recibió el estatuto privilegiado de municipium civium Romanorum con un senatus, aediles, duoviri y praefecti pro duoviris, el derecho a acuñar moneda y un desarrollo urbanístico de tipo romano: foro (El Raso), red de distribución de agua (MEZQUÍRIZ 1979), sistema de alcantarillado (CINCA 1983; CINCA/GARCÍA 1991), con toda seguridad un templo, termas, circo (junto al Parador Nacional), anfiteatro ${ }^{13}$, puente, embalse, etc. Otro aspecto que tuvo que influir en el florecimiento de este núcleo municipalizado fue Quintiliano, natural de Calagurris y maestro de Roma $^{14}$. En relación con la importancia de Quintialiano en la corte flavia están quizá los dos patronos de Calahorra que desempeñaron el cargo de iuridici en la Hispania Citerior (ESPINOSA 1983). La inestabilidad del s.III trajo consigo el amurallamiento de la ciudad, las viviendas extramuros se abandonaron y a lo largo del s. IV la ciudad dejó de ser el floreciente enclave de época augustea. En este mismo siglo floreció el Cristianismo en Calagurris (GARCÍA HERRERO 1984, GONZÁLEZ BLANCO 1981 y 1984) y con él, pero más tarde, el ideal ascético (YELO 1984). Importante va a ser para la vida cristiana el que Calahorra se convierta en sede episcopal (ESCRIBANO 1984) ${ }^{15}$. Durante la Tardía Antigüedad Calahorra no se diferencia de los otros enclaves del valle del Ebro y así se verá afectada por las invasiones del s. V y los bagaudas.

De esta exposición tan breve sobre la historia del municipio calagurritano, lo primero que queremos destacar es la importancia que este centro tuvo en la zona y las "numerosas" alusiones que a él encontramos en las fuentes, numerosas son si las comparamos con las que tenemos para otros enclaves romanos, como Vareia o

12. Sobre su adhesión al bando de Sertorio y sus consecuencias finales: ESPINOSA 1984; haciendo especial hincapié en los escasos datos que al respecto aportan las fuentes romanas, RAMÍREZ SÁDABA 1985.

13. Aunque se desconoce su localización, el hallazgo de una vasija de paredes finas con una escena de gladiadores en Celsa (Velilla de Ebro) y una leyenda referida a Calahorra prueba la existencia de estos juegos en dicho municipio, que no precisamente se tenían que realizar en un anfiteatro: BELTRÁN 1984.

14. Sobre su doctrina de la educación: GUILLÉN 1984; y para una visión concreta de la organización de la enseñanza en Calahorra: PÉREZ RODRÍGUEZ 1984.

15. De su vida episcopal hay que destacar el conflicto entre su obispo Silvano y otros obispos de la Tarraconense resuelto por el papa Hilario, sobre este pleito episcopal: ESPINOSA 1984, pp. 271 ss. 
Graccurris. Asímismo, la bibliografía también es muy amplia aunque gran parte de ella se limita a la publicación de hallazgos en Calahorra o los alrededores, en la mayoría de los casos sin contexto arqueológico, provenientes de colecciones particulares como la de Pedro Gutierrez Achútegui, de hallazgos casuales o de remodelaciones del actual casco urbano: fragmentos de mosaicos, lucernas, fragmentos cerámicos, objetos de metal, joyas, etc. Junto a estas publicaciones hay que situar aquellas que recogen muy escuetamente los resultados de los excavaciones de urgencia realizadas en solares de la ciudad.

Tres aspectos han contribuido en gran manera a la reconstrucción de la historia de este municipio romano y a potenciar los trabajos que sobre él mismo se han ido desarrollando. En primer lugar la creación en 1977 de la Asociación de Amigos de la Historia de Calahorra, amantes de su pasado y de su conservación ${ }^{16}$, y a los que debemos muchos de los descubrimientos arqueológicos producto de remodelaciones en el caso urbano. En segundo lugar la celebración del I Simposium de Historia de Calahorra en 1983, en el que se expusieron y se debatieron muchos de los aspectos de la historia de este municipio: problemas de fuentes, espectáculos públicos, el Cristianismo y la Iglesia calagurritana, aspectos de la vida y obra de dos personajes calagurritanos (Quintiliano y Prudencio), cuestiones de arqueología calagurritana, restos numismáticos, etc. Y por último el libro de Espinosa, Calagurris Iulia (1984), en el que se reconstruye el pasado de esta ciudad desde los primeros poblamientos en la zona hasta la época visigoda. Es la historia de la Calahorra romana como enclave dentro del valle del Ebro, como municipio bajo la jurisdicción del gobernador de la Tarraconense, afectado por los avatares del Imperio Romano desde la creación de un nuevo orden administrativo y político que supuso la integración jurídica de los provinciales y el consecuente desarrollo urbanístico, hasta el periodo de inestabilidad política e inseguridad general que se inauguró en el s. III d. C. y que supuso la ruina de las municipalidades en Occidente.

A pesar del avance de los estudios sobre Calagurris, las nuevas estructuras exhumadas hacen necesario un nuevo estudio de su ordenación urbana, con el fin de determinar con seguridad los elementos principales del esquema urbano de este municipio, fijar su emplazamiento en la actual ciudad y la extensión de su núcleo urbano, algo que ya hizó Gómez Pantoja en 1976 sirviéndose de la fotografía aérea (GÓMEZ PANTOJA 1976).

La segunda ciudad romana mencionada por las fuentes es GRACCURRIS, fundada en el año 179 a.C. por Tiberio Sempronio Graco sobre el oppidum indígena de Ilurcis; en un principio recibiría un estatuto peregrino y en época de Augusto o de Tiberio pasó a ser municipio latino . En la actualidad la polémica sobre su ubicación ya ha concluido y la mayoría de los investigadores sitúan la ciudad romana en las Eras de San Martín. La fundación de esta ciudad no se puede separar del proceso de

16. Un reflejo de su labor es la publicación en 1991 del libro Miscelánea. Arqueología de Calahorra (desglosado en bibliografía) en el que se recogen doce años de trabajos de esta asociación. 
conquista romana de Hispania, es fruto de una estrategia de conquista: crear una plataforma en la línea del Ebro para dominar a los arévacos, actuando Graccurris como un campamento de retaguardia cerca de la Celtiberia (HERNÁNDEZ VERA/ CASADO 1976).

La casi totalidad de las publicaciones en torno a este núcleo romano son de índole arqueológica, dos de ellas recogen los resultados de excavaciones arqueológicas llevadas a cabo en Alfaro en las últimas campañas (HERNÁNDEZ VERA 1989; MARTÍNEZ TORRECILLA 1993), las otras son publicaciones de hallazgos sueltos que muy poco nos aclaran sobre la historia de este núcleo romano.

La LIBIA de época romana fue sometida a un lento proceso de romanización como lo deja claro el estudio de los cortes estratigráficos y del material aqueológi co que es la base de la monografía de Marcos Pous a la que hemos aludido en el apartado dedicado a la II Edad del Hierro (MARCOS POUS 1979). La romanización se prolongó hasta época de Trajano, como lo atestiguan las estructuras urbanas exhumadas. Libia es una prueba más a lo ya ampliamente admitido sobre las vías de penetración del proceso romanizador, más lento a medida que nos acercamos al interior de la Península Ibérica.

En 1986 ESPINOSA Y RODRIGUEZ (Espinosa/ Rodríguez 1986) dan noticia de la necrópolis de Libia, descubierta en el momento de su destrucción y sobre la que pudieron realizar una excavación de urgencia en julio de 1982 pero ya era demasiado tarde, la necrópolis había sido arrasada. Del estudio de los materiales depositados en el Museo Provincial y de las observaciones sobre el terreno pudieron concluir que en la necrópolis eran patentes la existencia de dos ritos de enterramiento, incineración (urna cineraria) e inhumación (bajo tégulas, en sarcófagos y en sepulcro de lajas). El segundo rito se introdujo más tardíamente y de forma lenta, a la par que avanzaba el proceso de romanización.

Sobre la organización del territorio de Libia, ARIÑO (Ariño 1985) afirma la existenica, para nosotros dudosa, de una red de centuriación que estaría vinculada a esta ciudad.

La mayor parte de las publicaciones sobre TRITIUM se centran en su papel como centro productor de cerámica ( $c f r$. Industria alfarera) y son muy escasas las que aluden a su estatuto jurídico municipal. Tritium fue un oppidum berón que en la mitad del s. II fue elevado a la categoría jurídica de municipium, la causa de esta promoción jurídica hay que buscarla en la importancia que desde principios del Imperio tuvo su industria alfarera que acarreó un auge social, económico y cultural antes de que le fuese concedida la carta de municipalidad. Los trabajos en torno a su industria alfarera olvidan que convertirse en un importante centro alfarero tuvo como consecuencia inmediata la progresión jurídica de la ciudad y de las élites municipales. Al margen de los estudios sobre cerámica es de destacar el artículo de Espinosa/Pérez Rodríguez (ESPINOSA/ PÉREZ RODRÍGUEZ1982), que analiza el paso de Tritium de ciudad peregrina a municipio romano y las consecuencias que esto tuvo; y el de Navarro (NAVARRO 1989-1990) en torno a la existencia de una guarnición de la 
legio VII Gemina en Tritium, su ubicación, afirma el autor, tuvo una gran importancia estratégica para el control romano de la zona.

El último núcelo romano es VAREIA, localizado en el actual barrio logroñés de Varea. El verdadero conocimiento de este asentamiento comienza con el inicio de las labores arqueológicas sobre él mismo, labores que desde un principio fueron motivadas por la aplicación del Plan General de Ordenación Urbana de Logroño, tratándose siempre de excavaciones de urgencia que obligaban a una rápida actuación y que en la mayoría de los casos concluían con la destrucción de los restos exhumados. Así ocurrió en la campaña de mayo de 1979 en la que se excavó parte de un hipocausto romano (GALVE 1980) y una necrópolis medieval asentada sobre restos romanos (ANDRÉS 1980); en la campaña de 1980, en la que se exhumó una casa romana que después fue sepultada bajo un bloque de treinta y seis viviendas (ANDRÉS/ GALVE 1983); para las estructuras excavadas en la campaña de 1981 se llegó a una solución intermedia y los restos se conservan in situ en los sótanos de las casas (ANDRÉS/ GALVE 1983a); lo exhumado en 1982 también se conservó in situ pero nada se ha publicado hasta la fecha sobre sus resultados. En cambio, no corrieron la misma suerte los restos arqueológicos descubiertos desde 1983 hasta 1988 y sobre los que tampoco se ha publicado ningún informe, tan sólo algunos materiales (ANDRÉS/ LUEZAS 1989; ANDRÉS/ TIRADO 1991). Durante estos años las excavaciones se desarrollaron siguiendo el empuje urbanizador del barrio de Varea, ninguna zona se pudo excavar con la suficiente amplitud como para estudiar las pautas urbanas de este enclave.

A partir del año 1988 y 1989 las excavaciones se orientaron a conseguir una amplia zona excavada, dejaron de ser de urgencia, a excepción de pequeñas actuaciones, y se pudo reconstruir el trazado urbano, el sistema de suministro de aguas, la funcionalidad de los diferentes espacios y la evolución histórica del yacimiento (ESPINOSA 1989 y 1990): la dualidad de hábitat y la unidad de topónimo ${ }^{17}$, el origen militar del enclave vareyense y su existencia durante los siglos IV y V d.C. (ESPINOSA 1991; ESPINOSA/ TIRADO 1992). En la actualidad la casi más de media hectárea descubierta desde 1989 ha sido enterrada a pesar de que en octubre de 1990 se presentó un proyecto viable para la protección de los restos exhumados.

Se han definido las fases de ocupación del yacimiento pero siguen sin publicarse muchas de las campañas de excavación lo que impide completar la información que hasta ahora poseemos sobre él mismo. Falta también un estudio del entorno vareyense y del área de influencia de esta ciudad romana de la que se desconoce su estatuto jurídico ${ }^{18}$.

17. El primero en plantearse la dualidad del asentamiento berón-romano y la unidad de topónimo fue Pascual (1979, 1979a, 1981, 1983a y 1991) quien sitúa el núcleo berón en Monte Cantabria y el romano en el actual barrio logroñés de Varea. Recientemente Espinosa (1990) sugiere la posibilidad de que el asentamiento berón estuviese situado en La Custodia (Viana), dada la mayor entidad de éste con respecto a Monte Cantabria.

18. Aparece citada como mansio en el Itinerario Antoniniano. 


\section{NúCleos Menores ${ }^{19}$}

En el Inventario artístico de Logroño y su provincia ${ }^{20}$ se catalogan varios hallazgos de época romana que dan testimonio de la existencia de estos núcleos menores de población, núcleos que serían de carácter rural. La referencia que se hace a ellos se limita simplemente a constatar su existencia, no hay que olvidar el carácter de inventario que tiene la obra. Mención a estos y a otros núcleos menores tenemos también en la monografía de Elorza (ELORZA 1975) sobre escultura romana, en los dos corpora de epigrafía riojana(ELORZA 1980; ESPINOSA 1985), así como los estudios de carácter general sobre la arqueología en La Rioja (BAUTISTA 1977; PASCUAL/PASCUAL 1983 y 1984).

Con respecto a estos asentamientos rurales, principalmente sobre las villae, 1o publicado se limita a una mera mención de su localización. El hábitat rural en La Rioja en época romana no ha sido aún estudiado y aunque tenemos constatada la existencia de villae, aún no se ha excavado ninguna de ellas. En una región tan agrícolamente rica como La Rioja, en la que algunos hallazgos nos hablan de una producción oleícola (MORENO/ PASCUAL 1980; GONZÁLEZ/ HERNÁNDEZ VERA 1983), estudiar la implantación agraria romana es desde hace unos años un tema obligado y que aún no se ha emprendido con el debido rigor científico. No hay que olvidar que un trabajo de estas características supone la formación de un equipo, prospecciones sistemáticas y campañas de excavación que definan la ordenación del hábitat rural, el aprovechamiento de los recursos y funcionalidad de los espacios en una explotación agrícola ${ }^{21}$.

\section{Cuevas (Cfr. Antiguiedad Tardía)}

\section{INGENIERÍA ROMANA}

Los hallazgos de tramos de vías romanas en La Rioja y los estudios sobre puentes han contribuido en gran manera a ampliar el conocimiento que teníamos sobre la red viaria en esta región desde que en 1946 Govantes diese a conocer las primeras noticias sobre calzadas romanas. Pero a pesar de todo siguen existiendo muchas lagunas y problemas sin resolver que sólo un estudio de conjunto podría solucionar.

En lo referenta a las vías romanas hay que destacar el trabajo de Espinosa y Pascual (ESPINOSA/ PASCUAL 1981) en el que se dan a conocer diferentes des-

19. Un catálogo de los mismos en Espinosa 1981, p. 172 ss.

20. Moya como director del Museo de Logroño formó en 1969 un equipo con antiguos alumnos y compañeros de la Universidad de Zaragoza para catalogar el tesoro artístico de Logroño y de su provincia; en 1975 se publicaron el primer y segundo volumen (Ábalos-Cellorigo y Cenicero-Montalbo en Cameros, respectivamente) y en 1986 el tercero (Morales-San Martín).

21. En relación con la implantación agraria romana contamos con los trabajos sobre centuriaciones de Gómez-Pantoja (1976, 1977 y 1979) y de Ariño (1985, 1986 y 1990). 
cubrimientos arqueológicos en relación con la red viaria romana en el tramo central de La Rioja, enfocando el tema de las comunicaciones desde el aspecto de interrelación calzada-poblamiento pues no hay que olvidar que una vía determina la ubicación de un asentamiento y a la inversa, un asentamiento previo puede influir en el trazado de una vía. Posteriormente y con ocasión de la celebración del I Colquio de Historia de La Rioja Magallón (MAGALLÓN 1983) nos ofrece una puesta al día de los logros alcanzados en torno a este tema, así como de la metodología a seguir en trabajos futuros. Analizando tramos viales muy concretos tenemos el trabajo de Ariño y Núñez (ARIÑO/ NÚÑEZ 1990) en el que se reconstruye la vía paralela al río Alhama que unía las localidades de Contrebia Leukade (Aguilar del río Alhama) e Ilurcis (Alfaro); y el de Cinca (CINCA 1990) en el que estudia once kilómetros de vía en las cercanías de Calahorra y que formaría parte de la calzada romana que por la margen derecha del Ebro hacía el recorrido Tarraco-Caesaraugusta-Virovesca.

Dentro de este panorama no debemos olvidar los estudios de puentes que han contribuido notablemente a reconstruir el trazado viario. El trabajo de Martín-Bueno acerca del puente de Agoncillo sobre el Leza, el de Alfaro sobre el Alhama, y los de Sajazarra y Cihuri, de menor envergadura que los dos primeros (MARTíN-BUENO 1974); el puente romano sobre el Iregua, junto a Varea, publicado por primera vez por Pascual (PASCUAL 1978); y dos improbables puentes romanos sobre el Ebro, uno a la altura Logroño y bajo el actual puente de piedra (PASCUAL 1981: $167 \mathrm{ss}$. y 1991: 94 ss. y 117 ss.) y el otro a la altura de Varea (PASCUAL 1981: 167 ss. y Liz 1983: 150 y 1985: 73). Sentando las bases para un estudio exhaustivo de los puentes romanos en La Rioja está el trabajo presentado por Liz (LIZ 1983) en el I Coloquio de Historia de La Rioja, en el que postula como únicos criterios para la investigación arqueológica sobre puentes unas campañas de prospección intensiva, dejar a un lado los localismos y regionalismos y no olvidar los aspectos mencionados por Martín-Bueno (1974, pp. 233 ss.).

Otro aspecto dentro de las obras de ingeniería romana al que se ha prestado atención es al suministro de agua en las ciudades y al alcantarillado. Los restos de acueductos y cloacas que se conocen en La Rioja nos hablan de la actividad edilicia de ciudades como Calagurris y desde esta perspectiva hay que interpretar el acueducto romano de Lodosa-Alcanadre que abastecía de agua a Calagurris ${ }^{22}$; y la red calagurritana de alcantarillado estudiada desde un punto de vista arqueológico por Cinca (1985 y 1991).

\section{INDUSTRIA ALFARERA}

Los centros alfareros riojanos se concentran en el triángulo formado por el río Najerilla, el río Yalde y las sierras de Moncalvillo y el Serradero. Es una zona rica en arcilla, en agua y en espacios forestales, elemenos imprescindibles para la pro-

22. Para una reconstrucción de su trayecto: MEZQUÍRIZ 1979. 
ducción alfarera. A las características naturales de la zona hay que añadir su ubicación estratégica, por ella pasaban las vías que unían Virovesca-Caesaraugusta y Clunia-Tritium - Rioja Alavesa. La existencia de materia prima y las buenas comunicaciones impulsaron la producción de cerámica en la comarca tritiense que pasó a convertirse durante el Alto Imperio en uno de los centros productores de cerámica más importante de Hispania.

La importancia de la industria alfarera en nuestra región ha empezado a ser valorada a partir de los trabajos de Mezquiriz, Garabito y Solovera (cfr. Bibliografía). Gracias a ellos tenemos conocimiento de la ubicación de los principales centros de producción y de sus talleres, de los ceramistas, de sus motivos decorativos, formas y punzones, de las áreas de difusión y las zonas de comercialización, de los niveles de producción alcanzados, de su periodo de actividad, etc. En un principio los resultados de sus trabajos fueron fruto del estudio de materiales de superficie, obtenidos gracias a sus continuas visitas a la zona y a la inestimable colaboración de la Sociedad de Amigos de la Historia Najerillense. Pero no tardaron en realizarse las primeras excavaciones en esta región alfarera que aportaron importantes precisiones cronológicas, información sobre los diferentes tipos de hornos, la estructura de los talleres (horno, cubeta para batir la materia prima, lugar de almacenamiento de arcilla en bloques y vertederos), el proceso de fabricación, etc. El interés que estos trabajos sobre la producción alfarera riojana van despertando, combinándose ahora la prospección con la excavación, hace que cada año se descubran nuevos talleres y se llegue a diferenciar la producción de cada taller y el ámbito de dispersión de sus productos (GARABITO/ SOLOVERA 1990).

Los centros de producción son Bezares (Los Morteros), Arenzana de Arriba (La Puebla), Tricio (El Quemao, El Prado, Las Tejeras, Camino de Arcos), Camprovín, Arenzana de Abajo (finca Fuentecillas), Baños de Río Tobia (Bañuelos), Bobadilla y Manjarrés y sus zonas de comercialización son Mauritania, Lusitania, Betica (MÁRQUEZ 1985), centro de la Península Ibérica, costa mediterránea (área levantina). La época de auge de estos talleres comienza a mediados del s. I d. J.C. y se prolonga hasta mediados del s. II d. J.C., la actividad comenzó en Tricio y ante la creciente demanda surgieron otros talleres en las inmediaciones; a partir del s. III la actividad se vuelve a centrar de nuevo en Tricio y en el s. IV y V se traslada a Nájera (GARABITO 1983).

Pero al margen de la zona tritiense se ha atestiguado la presencia de alfares en otros puntos de La Rioja, como en Calahorra (CINCA 1985) y en Varea (ANDRÉS/ LUEZAS 1989 y 1993), aunque el área de difusión de sus productos tendría un carácter local, al contrario que la de Tricio. No parece ser ese el caso del alfar de La Maja al que González Blanco le atribuye un carácter industrial debido a las características de sus estructuras, su ubicación a las afueras de Calahorra y el grado de dispersión de sus productos (GÓNZALEZ BLANCO 1989). La importancia de este alfar radica en las características de sus producciones: es el único alfar conocido hasta ahora en La Rioja que fabrica cerámica común, engobada y de paredes finas (GONZÁLEZ BLANCO 1989; LUEZAS, 1991; PÉREZ BALLERTES, en prensa). 
La producción alfarera en época romana en La Rioja ha sido uno de los aspectos más tratados por historiadores y arqueólogos, en muchos casos son trabajos puramente descriptivos que ponen en nuestro conocimiento nuevos hallazgos, nuevos motivos decorativos o nuevas marcas de alfarero pero faltando casi siempre un tratamiento global de la economía y sociedad de esta región como parte del valle del Ebro.

\section{EPIGRAFÍA Y NUMISMÁTICA}

Dentro del campo epigráfico hay que distiguir dos tipos de publicaciones, las que estudian un epígrafe en concreto o un grupo, y los repertorios epigráficos. Entre las primeras contamos con el trabajo de Marcos Pous (MARCOS POUS 1974) sobre siete inscripciones halladas desde Alfaro a Herramélluri, siguiendo la vía romana Tarragona-Astorga; el de González Blanco y Espinosa (GONZÁLEZ BLANCO/ ESPINOSA 1974) sobre epigrafía en Cameros Nuevo (El Rasillo, Montemediano y Nieva de Cameros); el de Morestin (MORESTIN 1976) centrado en inscripciones de tipo religioso y en el que presenta dos epitafios inéditos (Pradillo y Nieva de Cameros); sobre un testimonio de epigrafía cristiana en Arnedo tenemos el trabajo de González Blanco (GONZÁLEZ BLANCO et alii 1977); el bien documentado estudio de Espinosa (ESPINOSA 1983) sobre la inscripción de Canales de la Sierra de seguro carácter funerario a pesar de la mención a la Fortuna Augusti; y también de este mismo autor la publicación las dos estelas anepígrafas con cabecera de disco de Nieva y Viniegra de Abajo (ESPINOSA 1985); por último la presentación que hacen Andrés y Tirado (ANDRÉS/ TIRADO 1991) de los testimonio epigráficos hallados en Varea hasta la campaña de 1988.

En 1975 Garabito y Solovera (GARABITO/ SOLOVERA 1975) publican una puesta al día de la epigrafía riojana, haciendo una síntesis actualizada y recogiendo los estudios de publicados hasta ese momento. En este artículo anuncian la próxima publicación del primer repertorio de epigrafía riojana, elaborado por Elorza (ELORZA et alli 1980). En este repertorio se recogen los epigrafes ya publicados, los inéditos, los que se hallaban por entonces en el Museo de La Rioja y los localizados por los mismos autores. En 1986 Espinosa publica el segundo y último repertorio de epigrafía riojana en el que presenta un total de setenta y siete inscripciones ordenadas según el criterio de "conjuntos" epigráficos (Graccurris, Calagurris, Barbariana-Vareia, Tritium Magallum, Cameros Nuevo, Canales de la Sierra y área Pelendona) (ESPINOSA 1986). Tanto un repertorio como otros son referencia obligada para cualquier estudio sobre época romana.

La casi totalidad de los trabajos en torno a hallazgos numismáticos son de carácter descriptivo, producto de hallazgos casuales o de campañas de excavación, desconociéndose en muchos su exacta procedencia. Su enfoque nos informa muy poco sobre la circulación monetaria en La Rioja y en ninguno de ellos se tiene en cuenta 
la importancia de la moneda para delimitar el área de influencia de las ciudades. Queda por hacer, por lo tanto, una revisión de la numismática en La Rioja desde la perspectiva de moneda y territorio ${ }^{23}$.

Pero el principal problema con el que se enfrenta la numimática hoy en día, y no sólo en La Rioja, es el gran número de monedas que están en propiedad de particulares y la pasión de los propietarios de detectores de metales, "domingueros de la arqueología", y en el peor de los casos abastecedores de un mercado negro contra el que cada día deben de enfrentarse los arqueólogos.

\section{RELIGIÓN}

Quizá sea éste uno de los aspectos más difíciles de tratar debido a la exigua documentación y a la problemática interpretación de muchos hallazgos arqueológicos. Es por eso que es escaso el número de trabajos en torno a la religión prerromana y romana en La Rioja.

En lo referente a las religiones indígenas contamos con el artículo de Albertos (ALBERTOS 1974) sobre la veneración a los montes, entre ellos a San Lorenzo; y los trabajos sobre hallazgos epigráficos de carácter religioso ( $c f r$. Epigrafía). Un estudio general de la religión indígena y romana a partir de los textos, de los restos epigráficos y de los manifestaciones escultóricas es el de Garabito y Solovera (GARABITO/SOLOVERA 1978), haciendo hincapié en los cultos que se han detectado en La Rioja, región en la que como en otras muchas se ha producido entre religión romana e indígena una asimilación y una yuxtaposición.

\section{TARDÍA ANTIGÜEDAD}

Durante los siglos IV y V el valle del Ebro se verá afectado por las invasiones de suevos, vándalos y alanos que a través de Roncesvalles penetran a la Península Ibérica en el 409; por las revueltas campesinas , los bagaudas, contra los grandes propietarios y el orden romano (BRAVO 1983 y 1985); y por el paso de los godos que a partir de entonces se asentaron definitivamente en Hispania ${ }^{24}$. Las oleadas de invasiones y de revueltas internas más los cambios de poder y de autoridad anunciaban ya el final de la Hispania Romana y el establecimiento de un orden nuevo. Hay una recesión de la vida urbana, se reaprovechan materiales anteriores para construir estructuras precarias y provisionales, la vida artesanal y comercial acompaña en su declive a la urbana.

23. Caso aparte son las publicación de tesorrillos que son testimonios de este tipo de ocultaciones en la Hispania Romana a partir del s. III: RODRÍGUEZ MARTÍNEZ 1992; ESPINOSA/TIRADO 1991.

24. Sobre la incidencia visigoda en La Rioja, a patir de la fuentes literarias y de los testimonios arqueológicos: ALONSO 1985. 
Los estudios sobre este periodo en La Rioja son hasta la fecha muy escasos. Por una parte contamos con el trabajo de Rodríguez Martínez (1992) sobre el tesorillo de Galiana que se engloba dentro del fenómeno de ocultaciones del s. IV en el valle del Ebro y en toda Hispania, como consecuencia de un periodo de inestabilidad e inseguridad $^{25}$. Consecuencia también de esta coyuntura histórica es la importancia que adquiere el hábitat en cuevas tras la caída del poder central romano hasta la Reconquista (GONZÁLEZ BLANCO et alii 1979) y el declive de la vida urbana como lo demuestra Espinosa (1991) para el caso de Vareia, en el que coinciden los testimonios de las fuentes escritas a nivel general y los datos aportados por las excavaciones de niveles del s.IV y $\mathrm{V}$ en este yacimiento.

\section{CONCLUSIÓN}

De todo este panorama bibliográfico lo primero que hay que destacar es que el conocimiento que tenemos sobre La Rioja en la Antigüedad depende en su mayor parte de los hallazgos arqueólogicos, las fuentes literarias griegas y latinas son muy parcas en lo referente al poblamiento indígena y romano en La Rioja. Hallazgos casuales, fuera de contexto estratigráfico, y excavaciones de urgencia son dos aspectos de la Arqueología Riojana que no ayudan en la reconstrucción del proceso histórico de esta zona del valle del Ebro. Pero el interés arqueológico de esta región, reconocido a nivel nacional como lo demuestra la celebración el Logroño del décimo séptimo Congreso Nacional de Arqueología (1983), y a nivel local, prueba de ello son los dos Coloquios sobre Historia de La Rioja (1982/1985) o el I Simposio de Historia de Calahorra (1983), pronostica futuros y fructíferos descubrimientos para reconstruir el pasado de La Rioja, pero siempre y cuando éstos sean fruto de proyectos de invetigación a medio y largo plazo.

Falta aún mucho por hacer, abundan las publicaciones sobre aspectos concretos y creemos que ya es hora de realizar estudios globales y de síntesis en los que las aportaciones de las primeras cobren algún sentido. El fenómeno, para nosostros de crucial importancia, de la integración indígena en el mundo romano en sus diferentes aspectos ha quedado enterrado por las descripciones arqueológicas y por las tipologías; la integración jurídica de las comunidades indígenas tan sólo se ha estudiado en detalle en algunos casos muy concretos, sigue faltando un estudio global; las cartas arqueológicas o los resultados de prospecciones han olvidado el problema base: la implantación de un nuevo sistema de ordenación del territorio, reaprovechándose, en la medida de lo posible, lo indígena; otro aspecto que hasta ahora tampoco ha sido tratado en profundidad es la explotación del suelo, las formas de propiedad y el mundo agrario indígena y romano

La clave del desarrollo de los estudios histórico-arqueológicos en La Rioja es abandonar el localismo y el eruditismo local; La Rioja, el valle medio del Ebro, la Tarraconense e Hispania son una pequeña parte de un Imperio y en ningún momento podemos desligarla del mismo para engrandecer el orgullo de "ser riojano".

25. Sobre un tesorillo oculto en Vareia: ESPINOSA/ TIRADO 1991. 


\section{BIBLIOGRAFIA}

AGUAROD, M.C. 1984

"Producciones engobadas en el municipium calagurritano": CBF, Madrid, 143-160.

ALBERTOS, M.L. 1974

"El culto a los montes entre galaicos, astures y berones y algunas deidades significativas": $E A A$ 6, 147-157.

ALONSO, A. 1985

"Visigodos y romanos de la provincia de La Rioja": Berceo 108-109, 7-31.

ALONSO, J.M. 1972-73

"Elementos romanos en la antigua Tritium": Zephyrus 23-24.

ALVÁREZ CLAVIJO, P./ MÍNGUEZ, J.A. 1989

"La cerámica de paredes finas procedente del yacimiento de Partelapeña (El Reda1, La Rioja)": Berceo 116-117, 49-63.

AMANTE, M./ GONZÁLEZ BLANCO, A. 1991

"El alfar de La Maja (Calahorra, La Rioja) y la perspectiva arqueológica de las nuevas tecnologías (IV Campaña de excavaciones, agosto 1991)": Estrato 3, 45-53.

AMANTE, M./ GONZÁLEZ BLANCO, A. 1992

"El alfar de La Maja (Pradejón-Calahorra, La Rioja) y su importancia para la epigrafía romana y calagurritana": Estrato 4, 47-54.

AMANTE, M./ GONZÁLEZ BLANCO, A. 1993

"Nuevos hornos y nuevos problemas en el alfar de La Maja. VII Campaña de Excavaciones. Septiembre de 1993": Estrato 5, 41-47.

AMARÉ, M.T. 1984

"Nota sobre una lucerna de la colección Gutierrez Achutegui en Calahorra": $C B F$, Madrid, 139-142.

AMARÉ, M.T. 1985

"Lucernas romanas de La Clínica (Calahorra)": II Col. de Hist. de La Rioja, Logroño, 163-172.

AMARÉ, M.T. 1987

Lucernas romanas en La Rioja, Logroño 1987.

AMARÉ, M.T. 1987

"Una nueva forma de lucerna en Terra Sigillata Hispanica": XVIII CNA (Islas Canarias 1985), Zaragoza, 885-888. 
AMARÉ, M.T. 1987b

"Lucernas en Terra Sigillata Hispánica": XVIII CNA (Islas Canarias), Zaragoza, 797804.

AMIGOS DE LA HISTORIA DE CALAHORRA 1991

"El yacimiento romano de El Calvario": Miscelánea. Arqueología de Calahorra, Logroño, 105-116.

AMIGOS DE LA HISTORIA DE CALAHORRA 1991a

"Hallazgos varios": Miscelánea. Arqueología de Calahorra, Logroño, 237-252.

AMIGOS DE LA HISTORIA DE CALAHORRA 1991b

"Solar PP. Agustinos. Avenida de la Estación": Miscelánea. Arqueología de Calahorra, Logroño, 253-256.

ANDRÉS, S. 1980

"Excavaciones arqueológicas en Varea (Logroño, La Rioja): La necrópolis medieval (1 Campaña, 1979)": Cuad. de Invest. 6.1 y 2, 51-63.

ANDRÉS, S. 1983

"Problemática de un yacimiento arqueológico de hábitat continuado: Varea (Logroño, La Rioja)": I Congr. de arqueología medieval española (Zaragoza 1982), v. 4, 507-516.

ANDRÉS, S./ GALVE, M.P. 1983

"Excavaciones arqueológicas en Varea (Logroño, La Rioja): Avance preliminar de la segunda campaña": XVI CNA (Murcia-Cartagena 1982), Zaragoza, 837-849.

ANDRÉS, S./ GALVE, M.P. 1983a

"Excavaciones arqueológicas en Varea. Tercera campaña": I Col. de Hist. de La Rioja (Logroño 1982), 107-126.

ANDRES, S./ GALVE, M.P. 1983b

"Problemática del yacimiento arqueológico de Varea (Logroño, La Rioja)": I Jornadas de arqueología en las ciudades actuales (Zaragoza 1982), 31-33.

ANDRÉS, S./ GALVE, M.P. 1984

"Hallazgos numismáticos en el yacimiento romano de Varea": CBF, Madrid, 69-75. ANDRÉS, S./ LUEZAS, R.A. 1989

"Un posible alfar de cerámica romana en Varea (Logroño, La Rioja)": Brocar 15, 151-166.

ANDRÉS, S./ LUEZAS, R. A. 1993

"Nuevos datos sobre un posible alfar de cerámica romana en Varea (Logroño, La Rioja)": Berceo 124, 73-88. 
ANDRÉS, S./ PÉREZ ARRONDO, C.L. 1983

"El poblamiento medieval en el yacimiento arqueológico de Monte Cantabria (Logroño, La Rioja)": I Congreso de Arqueología Medieval, v. IV, Zaragoza, 485505 .

ANDRÉS, S./ PÉREZ ARRONDO, C.L. 1991

"Excavaciones en el cerro medieval de Monte Cantabria (Logroño)": Estrato 3, 19-21.

ANDRÉS, S./ TIRADO, J.A. 1991

"Varea 1979-1988: Epigrafía y Numismática": Berceo 120, 7-64.

ARIÑO, E. 1985

"Centuriaciones en Libia (Herramélluri, Rioja)": XVII CNA (Logroños 1985), Zaragoza.

ARIÑO, E. 1986

Centuriaciones romanas en el valle medio del Ebro. Provincia de La Rioja, Logroño.

ARIÑO, E./ NÚÑEZ, J. 1990

"La organización de la red viaria en torno a Ilurcis-Gracurris": Simposio sobre la red viaria en la Hispania Romana (Tarazona 1987), Zaragoza, 253 ss.

BASTIDA, A.B./ HERAS, C.M. 1988

"Varea, una ciudad romana en La Rioja": Revista de Arqueología 82, 18-32.

BAUTISTA, J.J. 1977

"De Arqueología Riojana": Berceo 93, 259-285.

BELTRÁN, A. 1976

"Algunas cuestiones sobre localización de cecas ibéricas en relación con la zona de La Rioja": Cuad. de Invest. Geogr. e Hist. 2.2, 31-35.

BELTRÁN, A. 1983

"Estado actual de los estudios de arqueología riojana": I Col. de Hist. de La Rioja (Logroño 1982), Logroño, 7-12.

BELTRÁN, A. 1984

"Numismática antigua del área de Calahorra": $C B F$, Madrid, 53-67.

BELTRÁN, A. 1984

"Numismática antigua del área de Calahorra": $C B F$, Madrid, 53-67.

BELTRÁN, M. 1984

"Ludus calagurritanus: relaciones entre el municipium Calagurris Iulia y la colonia Victrix Iulia Celsa": CBF, Madrid, 129-138.

BERMÚDEZ, A. 1991

"Intervención de adecuación y rehabilitación en el sector arqueológico de La Clínica (Calahorra)": Estrato 3, 22-25. 
BRAVO, G. 1983

"Las revueltas campesinas del alto valle del Ebro a mediados del s. V d. C. y su relación con otros conflictos sociales contemporáneos (Una revisión sobre bagaudas)": I Col. de Hist. de La Rioja (Logroño 1982), 219-230.

BRAVO, G. 1986

"La Bagauda Hispana y la identidad de los possessores de la Tarraconense (puntualizaciones sobre la teoría social)": II Col. de Hist. de La Rioja (Logroño 1985), 197 209.

CANCELA, M.L./ MARTÍN-BUENO, M. 1984

"Arqueología clásica de Calahorra y su entorno": $C B F$, Madrid, 77-91.

CASTIELLA, A. 1977

La Edad de Hierro en Navarra y Rioja, Pamplona.

CASTIELLA, A. 1975

"Un nuevo yacimiento celtibérico en Arnedo (Logroño)": XIII CNA (Huelva 1973), Zaragoza, 627-632.

CILLERO, A. 1975

El Najerilla. Una cuenca desconocida, Logroño.

CINCA, J.L. 1985

"Un alfar de Sigillata Hispánica descubierto en Calahorra (La Rioja)": II Col. Hist. de La Rioja, Logroño, 143-153.

CINCA, J.L. 1990

"Tramo de calzada romana en el valle medio del Ebro": Simposio sobre la red viaria en la Hispania Romana (Tarazona 1987), Zaragoza, 95-112.

CINCA, J.L. 1991

"Restos arqueológicos en la finca La Maja": Miscelánea. Historia de Calahorra, Calahorra, 191-198.

CINCA, J.L. 1991a

"Un nuevo hallazgo arqueológico en Calahorra": Miscelánea. Arqueología de Calahorra, Logroño, 205-236.

CINCA, J.L./ GARCÍA, A. 1985

"Las cloacas romanas de Calahorra": XVII CNA (Logroño 1983), 797-808.

CINCA, J.L./ GARCÍA, A. 1991

"Un nuevo tramo de cloaca romana descubierto en Calahorra (La Rioja)": Miscelánea. Arqueología de Calahorra, Calahorra, 139-181.

CINCA, J.L./ GARCIA, A. 1991a

"Nota sobre el hallazgo de un molde de lucerna en Tricio (La Rioja)": Miscelánea. Arqueología de Calahorra, Calahorra, 183-186. 
CINCA, J.L./ PASCUAL, H. 1985

"Cerámicas grafitadas en la Torre de Campobajo. Término de Calahorra (La Rioja)": XVII CNA (Logroño 1983), Zaragoza, 623-630.

CINCA, J.L./ RUIZ, J.A. 1991

"Hallazgo de una joya de época romana en Calahorra (La Rioja)": Miscelánea. Arqueología de Calahorra, Logroño, 187-190.

DIARTE, M.P. 1987

Bases arqueológicas para el estudio de la II Edad del Hierro en la cuenca Alta y Media del Ebro, Memoria de licenciatura (inédita), Zaragoza.

DUPRE, N. 1984

"Calzada de los Romanos au Camino de Santiago dans La Rioja": Caesarodunum 19, 143-154.

ELORZA, J.C. 1975

Escultura romana en La Rioja, Logroño.

ELORZA, J.C. 1980

Inscripciones romanas en La Rioja, Logroño.

ESCRIBANO, M.V. 1984

"La Iglesia calagurritana entre ca. 457 y 465. El caso del obispo Silvano": CBF, Madrid, 265-272.

ESPINOSA, U.

"Cabeza femenina de época romana descubierta en Alfaro (La Rioja)": Museos 2, 85-88.

ESPINOSA, U. 1981

Estudio de bibliografía arqueológica riojana: Prehistoria e Historia Antigua, Logroño.

ESPINOSA, U. 1982

"Excavaciones en el municipio Calagurris Iulia":Exposición de arqueología calagurritana, Calahorra, 31-35.

ESPINOSA, U. 1983

"Iuridici de la Hispania Citerior y patroni de Calagurris": Gerión 1, 305-325.

ESPINOSA, U. 1983a

"Fortuna Augusti. Ein neues epigraphisches Zeugniss aus Hispania Citerior": ZPE 51, 199-203.

ESPINOSA, U. 1984

"Calagurris y Sertorio": CBF, Madrid, 189-199. 
ESPINOSA, U. 1984a

Calagurris Iulia, Logroño 1984.

ESPINOSA, U. 1985

"Antiguas estelas discoideas en La Rioja": Berceo 108-109, 81-94.

ESPINOSA, U. 1986

Epigrafía romana de La Rioja, Logroño

ESPINOSA, U. 1989

"La ciudad romana de Varea": Estrato 1, 4-9.

ESPINOSA, U. 1990

Vareia. Enclave romano en el valle del Ebro, Logroño.

ESPINOSA, U. 1991

"El siglo V en el valle del Ebro: Arqueología e Historia": Antig. Crist. 8, Murcia, 275-288.

ESPINOSA, U. 1992

"Los castros sorioano-riojanos del Sistema Ibérico: nuevas perspectivas": II Symposium de Arqueología Soriana, Soria, 901-913.

ESPINOSA, U. 1993

"El gentilicio Berones en el topónimo Logroño": Avrea Saecula, Barcelona.

ESPINOSA, U./ GONZÁLEZ BLANCO, A. 1974

"Más epigrafía romana en Cameros Nuevo": Berceo 87.

ESPINOSA, U./ GONZÁLEZ BLANCO, A. 1976

"Urnas y otras piezas de cerámica excisa en la provincia de Logroño": Berceo 90, 83102.

ESPINOSA, U./ GONZÁLEZ BLANCO, A. 1976A

"La necrópolis del poblado celta-romano de Santa Ana (Entrena, Logroño)": AEA 46, 164-174

ESPINOSA, U./ GONZÁLEZ BLANCO, A. 1977

"Noticia de un yacimiento arqueológico prerromano y romano situado en el Cerro y zona de Santa Ana (Entrena, Logroño)": XIV CNA (Vitoria 1975), Zaragoza, 10211048.

ESPINOSA, U./ GONZÁLEZ BLANCO, A. 1977a

"En torno a los orígenes de Medrano": Berceo 92 (1977), 111-125.

ESPINOSA, U./ GONZÁLEZ BLANCO, A. 1978

"El cerro de Santa Ana (Entrena, Logroño) y su datación C-14": C14 y Prehistoria de la Península Ibérica, Madrid, 111-112. 
ESPINOSA, U./ NOACK, S. 1992

"Una pieza de orfebrería bajoimperial en Varea (Logroño, La Rioja)": MDAI (M), 170-184.

ESPINOSA, U./ PASCUAL, J.M 1981

"Aportación al estudio de las vías romanas en el Ebro Medio. Desembocaduras del Iregua y del Leza": Berceo 101, 69-88.

ESPINOSA, U./ PÉREZ RODRÍGUEZ, A. 1982

"Tritium Megallum; de ciudad peregrina a municipio romano": AEA 55, 65-89.

ESPINOSA, U./ RODRIGUEZ, M.P. 1986

"La necrópolis de Libia de los Berones": TP 43, 227-238.

ESPINOSA, U./ TIRADO, J.A. 1991

"Las monedas del Imperio Galo en Vareia (Varea, Logroño)": Estrato 3, 26-30.

ESPINOSA,U./ TUDANCA, J.M. 1990

"Varea (Logroño). Presente y futuro de un yacimiento romano": Estrato 2, 17-21.

FERNÁNDEZ DE BOBADILLA, F. 1976

Apuntes para la historia de Arnedo, Arnedo, 71-73.

FERNÁNDEZ IBÁÑEZ, C. 1983

"Desarrollo arqueológico-cultural de la comarca de Haro (La Rioja)": I Col. de Hist. de La Rioja (Logroño 1982), 199-204.

GAJATE, J.M./ PASCUAL, J.M. 1986

"Sobre la ciudad berona de Varia": II Col. de Hist. de La Rioja (Logroño 1985), 113116.

GAJATE, J.M./ PASCUAL, J.M. 1986a

"Un nuevo yacimiento celtibérico en Bergasa (Logroño)": XV CNA (Lugo 1977), Zaragoza, 699-704.

GALVE, M.P. 1978

"Fuentes bibliográficas para la arqueología prerromana de La Rioja": Cuad. de invest. Geogr. e Hist. 4.1, 53-73.

GALVE, M.P. 1980

"Excavaciones arqueológicas en Varea (Logroño, La Rioja): El hipocausto romano":

Cuad. de Invest. Geogr. e Hist. 6.1 y 2, 19-49.

GALVE, M.P. 1983

"El amuleto fálico con cabeza de toro de Varea (La Rioja)": Caesaraugusta 57-58, 11-33.

GARABITO, T./ SOLOVERA, M.E. 1975

"Aras y estelas romanas del territorio berón (Rioja)": Durius 3.2, 325-343. 
GARABITO, T. 1978

"Las zonas de comercialización de los alfares romanos riojanos": Berceo 93 (1977), 155-170.

GARABITO, T. 1978a

Los alfares romanos riojanos. Producción y comercialización, Madrid 1978.

GARABITO, T. 1983

"El centro de producción de sigillata hispánica tardía en Nájera": I Col. de Hist. de La Rioja, Logroño 1983, 187-197.

GARABITO, T. 1986

"Hallazgo de un alfar romano del siglo IV en Tricio (septiembre-85)": Berceo 110$111,63-74$.

GARABITO, T. 1993

"La producción de lucernas en Tricio": Estrato 5, 35-40.

GARABITO, T./ SOLOVERA, M.E. 1978

"La religión indígena y romana en La Rioja de los berones": Hispania Antiqua 8, 143-199.

GARABITO, T./ SOLOVERA, M.E. 1986

"Los nombres de los ceramistas romanos de La Rioja: nuevas aportaciones": II Col. Hist. de La Rioja (Logroño 1985), Zaragoza, 117-127.

GARABITO, T./ SOLOVERA, M.E. 1990

"Excavaciones arqueológicas en Tritium Magallum (Tricio, Rioja). Descubrimiento de nuevos alfares": Estrato 2, 36-42.

GARABITO, T./ SOLOVERA, M.E. 1990A

"Los talleres de Tritium Magallum. Nuevas aportaciones": HA 14, 69-89.

GARABITO, T./ SOLOVERA, M.E. 1991

"Tritium Megallum. Centro productor de cerámica común romana": Estrato 3, 12-15.

GARABITO, T./ SOLOVERA, M.E. 1992

"Las firmas de fabricantes de moldes en Tritium Megallum": Estrato 4, 9-16.

GARABITO, T./ VALLALTA, M.P. 1984

"¿Cantaban los calagurritanos en la Antigüedad?": CBF, Madrid, 291-297.

GARABITO, T. ET ALII 1986

"Los alfares romanos de Tricio y Arenzana de Arriba: estado de la cuestión": II Col. Hist. de La Rioja (Logroño 1985), Zaragoza, 129-142. 
GARABITO, T. et alii 1986a

"Hallazgo de un alfar romano del siglo IV en Tricio (septiembre-85)": Berceo $110-$ $111,63-74$.

GARCÍA, A./ MANZANARES, M.A. 1991

"Materiales procedentes del solar La Clínica": Miscelánea. Arqueología de Calahorra, Logroño, 117-137.

GARCÍA AGUINAGA, J.L. 1984

"Un testimonio de celebración de las saturnales en Calahorra": $C B F$, Madrid, 201205.

GARCÍA ÉCIJA, A. 1986

"El yacimiento prerromano del cerro de San Justo (Cenicero, La Rioja)": II Col. de Hist. de La Rioja, (Logroño 1985), Zaragoza, 87-94.

GARCÍA HERRERO, G. 1984

"Del municipio pagano al municipio cristiano. Rasgos en la obra de Aurelio Prudencio": $C B F$, Madrid, 217-224.

GARCÍA PRADO, J. (Dir.) 1983

Historia de La Rioja. Vol I: Prehistoria, protohistoria. Edad Antigua, Logroño.

GARCÍA RAMÍREZ, S. 1986

"Pintura mural romana de La Clínica (Calahorra)": II Col. de Hist. de La Rioja (Logroño 1985), 173-181.

GIL DEL RÍO, A. 1981

El enigma de los berones, Zaragoza.

GIL DEL RÍO, A. 1988

Los Berones. A la búsqueda del pasado, Madrid.

GÓMEZ MARTÍNEZ, J.R. 1984

"La ciudad romana de Varea (Logroño)": Revista de Arqueología 49, 56-57.

GÓMEZ-PANTOJA, J. 1976

"La ciudad romana de Calahorra": Symposium de ciudades augústeas II, Zaragoza, 185-188.

GÓMEZ-PANTOJA, J. 1977

"Sobre un posible catastro romano en el límite navarro-riojano": Príncipe de Viana 148-149, 423-433.

GÓMEZ-PANTOJA, J. 1979

"Vestigios de una posible centuriatio romana en las cercanías de Alfaro (Logroño)": XV CNA (Lugo 1977), Zaragoza, 929-936. 
GONZÁLEZ BLANCO, A. 1977

"Epigrafía cristiana en una iglesia rupestre de época romano-visigoda en Arnedo (Logroño)": XV CNA (Lugo 1977), Zaragoza, 1129-1142.

GONZÁLEZ BLANCO, A. 1981

"El Cristianismo en el municipio de Calahorra del 380 al 410": MHA 5, 195-202.

GONZÁLEZ BLANCO A. 1984

"El hambre de Calahorra del año 72 a.C.": CBF, Madrid, 207-215.

GONZÁLEZ BLANCO, A. 1984a

"Los orígenes cristianos de la ciudad de Calahorra": $C B F$, Madrid, 231-245.

GONZÁLEZ BLANCO, A. 1987

Diccionario de toponimia actual de La Rioja, Murcia.

GONZÁLEZ BLANCO, A. 1989

"El alfar romano de La Maja. Pradejón-Calahorra": Estrato 1, 50-55.

GONZÁLEZ BLANCO, A./ HERNÁNDEZ VERA, J.A. 1983

"Más restos de industria oleícola romana en La Rioja": II Congreso sobre la producción y comercio del aceite en la Antigüedad, Madrid, 611-616.

GONZÁLEZ BLANCO, A./ PASCUAL, H. 1991

"La joya de Calahorra testimonio de una época de esplendor": Miscelánea. Arqueología de Calahorra, Calahorra, 15-53.

GONZÁLEZ BLANCO, A. et alii 1979

"La población de La Rioja durante los siglos oscuros (IV-X)": Berceo 96, 81-111.

GONZÁLEZ BLANCO, A. et alii 1985

"Los fosos del yacimiento de Santa Ana (Entrena, La Rioja). ¿Un quemadero de ofrendas?": XVII CNA (Logroño 1983), Zaragoza, 435-449.

GUERRERO, A. 1984

"La vida cotidiana en la Calahorra Cristiana: la casa y sus problemas": $C B F$, Madrid, 283-290.

\section{GUILLÉN, M.G. 1984}

"La educación del hombre a la luz de la doctrina de Quintiliano": $C B F$, Madrid, 299309.

HERAS Y NUÑEZ, M.A. 1988

"Existencia de un alfar romano en el término de Santa Cruz de Baños de Río Tobía (La Rioja)": Berceo 114-115, 61-104.

HERAS Y NÚÑ̃Z, M.A. 1988

"Avance al estudio de la cerámica común romana en La Rioja": Berceo 114-115, 51 61. 
HERAS Y NÚÑEZ, M.A. 1991

"La cerámica común del alfar de La Maja (Calahorra, Rioja): Campañas 1987-1988": Berceo 121, 61-102

HERNÁNDEZ, M.A. 1984

"Objetos metálicos de época romana aparecidos en Calahorra": $C B F$, Madrid, 161172.

HERNÁNDEZ VERA, J.A. 1978

"Las ruinas de Inestrillas": Caesaraugusta 45-46, 63-66.

HERNÁNDEZ VERA, J.A. 1982

Las ruinas de Inestrillas. Estudio arqueológico, Logroño.

HERNÁNDEZ VERA, J.A. 1989

"Excavaciones arqueológicas en las ruinas de Inestrillas. Aguilar del Río AlhamaCampaña 1989": Estrato 1, 15-22.

HERNANDEZ VERA, J.A. 1989a

"Excavaciones arqueológicas de Alfaro": Estrato 1, 35-39.

HERNÁNDEZ VERA, J.A. 1990

"Contrebia Leukade. Aguilar del río Alhama": Estrato 2, 4-9.

HERNÁNDEZ VERA, J.A. 1991

"Acerca de una vasija celtibérica con decoración de cabezas humanas hallada en las excavaciones de Contrebia Leukade": Estrato 3, 40-44.

HERNÁNDEZ VERA, J.A. 1992

"Consideraciones en torno al parque arqueológico de Contrebia Leukade": Estrato 4, 4-8.

HERNÁNDEZ VERA, J.A./ MARTÍNEZ TORRECILLA, J.M. 1993

"Consideraciones sobre la última ocupación de las ruinas de Contrebia Leukade. Aguilar del río Alhama": Estrato 5, 16-22.

HERNÁNDEZ VERA, J.A. et alii 1989

"Excavaciones arqueológicas en las ruinas de Inestrillas. Aguilar del río AlhamaCampaña 1989": Estrato 1, 15-22.

HERRERA, J.C. 1986

"Las contramarcas de la ceca de Gracurris": II Col. de Hist. de La Rioja (Logroño 1985), Logroño, 183-195.

JIMÉNEZ, M.C. et alii 1985

"Hallazgos numismáticos en Varea en la campaña de 1983": XVII CNA (Logroño 1983), Zaragoza, 759-775. 
JORDÁN, J.F. 1984

"La pervivencia del paganismo en la Calahorra de comienzos del siglo V": CBF. Madrid, 247-258.

LABEAGA, J.C. 1990

"Las monedas de Uarakos y Calagurris en el poblado berón de La Custodia, Viana (Navarra)": Berceo 118-119, 131-148.

LASHERAS, J.A. 1984

"Restos musivos romanos en Calahorra": CBF, Madrid, 121-128.

LILLO, P./ PASCUAL, H.

"Noticia de una joya con tema virgiliano aparecida en Calahorra (La Rioja)": Symposio conmemorativo de la muerte de Virgilio, Murcia.

LIZ, J. 1983

"Los puentes romanos en La Rioja. Estado actual de las investigaciones y nuevas perspectivas": I Col. de Hist. de La Rioja (Logroño 1982), 147-151.

LIZ, J. 1985

Puentes romanos en el Convento Jurídico Caesaraugustano, Zaragoza, 65-67

LUEZAS, R.A. 1988

"Avance al estudio de la cerámica común romana en La Rioja": Berceo 114-115, 51 60 .

LUEZAS, R.A. 1988-89

"Una estampilla de dolium de Varea (Logroño, La Rioja)": Caesaraugusta 166-167, 159-165.

LUEZAS, R.A. 1991

"La cerámica común del alfar de La Maja (Calahorra, La Rioja): Campañas 19871988": Berceo 121, 61-102.

LUEZAS, R.A./ SAEN PRECIADO, M.P. 1989

La cerámica romana de Varea, Logroño.

LUEZAS, R.A. et alii 1992

"El alfar romano de La Maja (Calahorra) Horno II. Campaña 1989: Materiales cerámicos": Estrato 4, 29-34.

MAGALLÓN, M.A. 1983

"La red viaria romana en La Rioja": I Col. de Hist. de La Rioja (Logroño 1982), Logroño, 153-166.

MARCO, F. 1978

Las estelas decoradas de los conventos Caesaraugustano y Cluniense, Zaragoza. 
MARCOS POUS, A. 1974

"Aportaciones a la Epigrafía Romana de La Rioja": Berceo 86.

MARCOS POUS, A. 1979

Trabajos arqueológicos de la Libia de los berones, Logroño.

MÁRQUEZ, C. 1985

"Terra sigillata hispánica de los talleres riojanos en la provincia de Córdoba": II Col. Hist. de La Rioja, Logroño, 155-162.

MARTÍN-BUENO, M. 1974

"Nuevos puentes romanos en La Rioja": EAA 5, 228-235.

MARTÍN-BUENO, M. 1974a

"Numismática antigua en el Museo Provincial de Logroño": Acta Numismática, 6585.

MARTÍN-BUENO, M. 1975

"La necrópolis medieval y las estelas indígenas de Hormilleja (Logroño)": $N A H$ Prehistoria 4, 356 ss.

MARTÍN CAMINO, M. 1984

"Los espectáculos públicos en la Calahorra de Prudencio": CBF, Madrid, 225-230.

MARTÍNEZ TORRECILLA, J.M., 1993

"Excavaciones arqueológicas en las Eras de la cárcel. Alfaro": Estrato 5, 23-26.

MEDRANO, M. 1989

"Aproximación a la circulación monetaria en los territorios interiores del norte de la Península Ibérica durante los primeros Julio-Claudios": Berceo 116-117, 65-80.

MÉNDEZ, A./ MORENO F.J.

"La gema entallada de Santa Ana (Entrena)": Museos 2, 89-93.

MEZQUÍRIZ, M.A. 1975

"Nuevos hallazgos sobre fabricación de sigillata hispánica en la zona de Tricio": Misc. Arq. dedicada por sus alumnos al Prof. Beltrán, Zaragoza, 231-243.

MEZQUÍRIZ, M.A. 1976

"Hallazgo de un taller de sigillata hispánica en Bezares (Logroño)": Príncipe de Viana 144-145, 299-304.

MÉZQUIRIZ, M.A. 1979

"Un acueducto romano de Lodosa Alcanadre": Trabajos de Arqueología en Navarra $1,139-148$.

MEZQUÍRIZ, M.A. 1980

"Un taller de Terra Sigillata Hispánica en Bezares": Congressus Dvodecimvs Rei Cretariae Favtorvm Rvtenvs. 
MEZQUÍRIZ, M.A. 1982

"Decouverte d'un four romain à Camprovin (Logroño)": Revue Archéologique de l'Est et du centre-est 33.

MEZQUÍRIZ, M.A. 1983

"Alfar romano de Bezares": I Col. de Hist. de La Rioja, Logroño 1983, 167-173.

MEZQUÍRIZ, M.A. 1993

"Algunas piezas singulares halladas en el alfar de Bezares (La Rioja)": Cuad. de Arqu. de la Univ. de Navarra 1, 279-284.

MIGUEL, F.J./ MORALES, A. 1984

"Informe sobre los restos faunísticos recuperados en el yacimiento del cerro de Santa Ana (Entrena, Logroño): Berceo. Ciencias 1, 49-165.

MIGUEL, F.J./ MORALES, A. 1986

"Nuevas recuperaciones de fauna en el yacimiento del cerro de Santa Ana (Entrena, La Rioja)": II Col. Hist. de La Rioja (Logroño 1985), Zaragoza, 103-111.

MÍNGUEZ, J.A. 1989

"La producción de paredes finas con decoración a molde del ceramista Caius Valerius Verdullus y su difusión por el valle del Ebro": Actas del Congreso de Lezoux (Lezoux 1989), Marsella, 181-189.

MORENO, F.J./ PASCUAL, H. 1977-78

"Bergasa (Logroño), un yacimiento importante para el estudio de la cerámica celtibérica del Valle del Ebro": AEA 50-51, 405-416.

MORENO, F.J./ PASCUAL, M.P. 1980

"Prensas de aceite romanas en La Rioja": AEA 53, 199-210.

MORESTIN, H. 1976

"Inscripciones religieuses et pierres inedites ou peu connues de la province de Logroño": AEA 49, 181-192.

MOSTALAC, A. 1984

"Notas para el estudio de la pintura mural romana de Calahorra": $C B F$, Madrid, 93120.

MOYA, J.G. (dir.) 1975-1986

Inventario artístico de Logroño y su provincia La Rioja, Madrid.

NAVARRO, M. 1989-90

"Una guarnición de la legión VII Gémina en Tritium Magallum": Caesaragusta 66$67,217-226$.

NÚÑEZ MARCEN, J. et alii 1990

"Pavimentos de opus signinum de Alfaro": Estrato 2, 31-35. 
ORTEGO, T. 1976

"Un yacimiento arqueológico inédito. El Patín en Estollo": Bolet. de la Asoc. de Amigos de la Arqueología 5, 23-25

PAGÉS, J. 1978

"Trouvaille d'une bronze colonial d'Auguste sur le site des Moulies. Commune de Bastennes (Landes)": Cuad.de Invest. Geogr. e Hist. 4.2, 83-89.

PASCUAL, H. 1985

"Un colgante de cerámica procedente de la zona de Tricio": XVII CNA (Logroño 1983), Zaragoza, 793-796.

PASCUAL, H./ PASCUAL, M.P. 1983

"Nuevos yacimientos arqueológicos en el valle del Cidacos: Préjano, Navalsaz y Garranzo": I Col. de Hist. de La Rioja (Logroño 1982), Logroño, 205-218.

PASCUAL, H./ PASCUAL, M.P. 1984

Carta arqueológica de La Rioja: I. El Cidacos, Logroño.

PASCUAL, J.M. 1979

Varia de los berones. Los berones en la desembocadura del Iregua, Memoria de licenciatura (inédita), Zaragoza.

PASCUAL, J.M. 1979a

"Hallazgos superficiales en Monte Cantabria (Logroño)": Cuad. de Invest. Geogr.e Hist. 5.1 (1979), 51-64.

PASCUAL, J.M. 1981

"En torno a los orígenes de la ciudad de Logroño": Berceo 100, 167-181.

PASCUAL, J.M. 1983A

"La cronología de Vareia (Varea, Logroño)": I Col. de Hist. de La Rioja (Logroño 1982), 127-134.

PASCUAL, J.M. 1991

Origen de la ciudad de Logroño. Historia Antigua del municipio logroñés, Logroño.

PASCUAL, M.P. 1991

"Abastecimiento de agua a Calagurris": Miscelánea. Arqueología de Calahorra, Calahorra, 55-104.

PEREX-AGORRETA, M.J. 1986

"Vascones en La Rioja en época romana (según las fuentes literarias)": II Col. de Hist. de La Rioja (Logroño 1985), Logroño.

PÉREZ ARRONDO, C.L. 1979

"Excavaciones arqueológicas en Monte Cantabria. 1977 Informe preliminar": Cuad. de Invest. Geogr. e Hist. 5.1, 65-79. 
PÉREZ ARRONDO, C.L. 1983

"Monedas medievales en el yacimiento de Monte Cantabria": Numisma 180-185, 191-200.

PÉREZ ARRONDO, C.L. 1990

"El yacimiento arqueológico de Monte Cantabria (Logroño)": Estrato 2, 10-13

PÉREZ ARRONDO, C.L. ET ALII 1990

"El recinto medieval de Monte Cantabria (Logroño, La Rioja)": Brocar 16, 7-18.

PÉREZ BALLERTES, J.

"Las cerámicas engobadas del alfar de La Maja" Berceo (en prensa).

PÉREZ RODRÍGUEZ, A. 1984

"La organización de la enseñanza en la Calahorra romana a través de los datos biográficos de M. Fabio Quintiliano y de Aurelio Prudencio Clemente": $C B F$, Madrid, 311-315.

PÉREZ VILATELA, L. 1988

"Génesis autorística de las fuentes del siglo I a.C. sobre los berones":Berceo 114$115,39-50$.

POMARES, A. 1984

"La educación en Prudencio": CBF, Madrid, 259-264.

RAMÍREZ SADABA, J.L. 1985

"Limitaciones inherentes a las fuentes literarias: consecuencias de la guerra sertoriana para Calagurris": Gerión 3, 231-243.

RODANÉS, J.M.

"Fíbulas zoomorfas en La Rioja. Los hallazgos de la Cueva del Tejón y Monte Cantabria": Caesaraugusta 61-62.

RODRÍGUEZ MARTÍNEZ, M.P. 1991

"Excavación de urgencia en el solar conocido como a Casa del Oculista": Estrato 3 , pp. 54-55.

RODRÍGUEZ MARTÍNEZ, M.P. 1992

Aproximación a la economía de fines del siglo IV y principios del siblo $V$ en La Rioja: el tesorillo de Galiana, Logroño.

SÁENZ PRECIADO, J./ SAENZ PRECIADO, M.P. 1993

"Marcas y grafitos en sigillata aparecidos en Libia, Herramélluri-La Rioja": Estrato $5,27-34$.

SÁENZ PRECIADO, M.P. 1992

"Entalle depositado en el Museo de Nájera (La Rioja)": Berceo 122, 161-167. 
SÁNCHEZ TRUJILLANO, M.T. 1989

Cerámica histórica de La Rioja, Logroño.

SÁNCHEZ TRUJILLANO, M.T. 1989

"El Museo oculto. La sección de arqueología": Estrato 1, pp. 10-13.

SINTAS, M.E. 1984

"Agricultura y alimentación en la Calahorra de los siglos IV y V": $C B F$, Madrid, 277-282.

SOLOVERA, M.E. 1980

"Memoria de las excavaciones arqueológicas realizadas en Arenzana de Arriba. Campañas 1978-1989": NAH.

SOLOVERA, M.E. 1983

"El centro de producción de sigillata hispánica de Arenzana de Abajo": I Col. Hist. de La Rioja, Logroño, 175-185.

SOLOVERA, M.E. 1987

Estudios sobre la historia económica de La Rioja romana, Logroño.

TIRADO, J.A. 1993

"Excavación en el solar de la antigua fábrica de Torres. Calahorra": Estrato 5, 48-55.

VALDIVIESO, R. M. 1984

Religiosidad antigua y religiosidad popular en la zona norte del Sistema Ibérico, Mem. de Licenciatura (inédita), Madrid.

VALDIVIESO, R.M. 1986

"Los orígenes de un culto en los montes de La Rioja: Valvanera": II Col. de Hist. de La Rioja (Logroño 1985), 219-232.

VALLALTA, M.P. 1985

"Un molde cerámico del ayuntamiento de Logroño": XVII CNA (Logroño 1983), Zaragoza, 787-791.

VALLALTA, P. 1986

"Una balanza de precisión procedente del yacimiento de Santa Ana": II Col. Hist. de La Rioja (Logroño 1985), Zaragoza, 95-102.

VELAZA, J. 1991

"Nota sobre algunoa falsos epigráficos: un pretendido testimonio de GracchurrisAlfaro": Caesaraugusta 68, 71-75.

VILLACAMPA, M.A. 1978

"Los berones a través de las fuentes literarias": Caesaraugusta 45-46, 48 ss. 
VILLACAMPA, M.A. 1979

"Historiografía de Monte Cantabria (Logroño)": Cuad. de Invest. Geogr. e Hist. 5.1, 41-50.

VILLACAMPA, M.A. 1984

"Calahorra y su entorno a través de las fuentes escritas desde sus orígenes hasta el s. IV d.C.": $C B F$, Madrid, 173-187.

VV.AA. 1983

La Rioja y sus gentes, Logroño.

YELO, A. 1984

"El ascetismo en la Calahorra de Prudencio": $C B F$, Madrid, 273-276. 